\title{
Requirements Identification for Migration of Higher Educational Resources to Cloud
}

\author{
Bariah Al-Jebreen \\ Research Student \\ College of Computer and \\ Information Sciences \\ Prince Sultan University \\ KSA, Riyadh
}

\author{
Ajantha Dahanayake \\ Professor, \\ College of Computer and \\ Information Sciences \\ Prince Sultan University \\ KSA, Riyadh 2nd
}

\author{
Liyakathunisa Syed \\ Assistant Professor, \\ College of Computer and \\ Information Sciences \\ Prince Sultan University \\ KSA, Riyadh 2nd
}

\begin{abstract}
Cloud represents an important change in the way information technology is used. Cloud makes it possible to access work anywhere anytime and to share it with anyone [1]. In order to gain the benefits of the cloud to be used in educational system in KSA, this paper investigates the Requirements Identification for Migration of Higher Educational Resources to Cloud with a view of consolidating a framework that defines a systematic implementation of educational cloud in the Higher Educational Systems for KSA. The proposed framework has four main stages. The first is higher educational organizations assessment, in this stage the organizations must determine their economic objectives, as they relate to, finances, customers and internal infrastructure. The second stage is creating the profile for higher education organization in KSA. Oorganization's profiles must be created through a cross-analysis to resolve critical limitations that may delay migration to the cloud, the outcomes of the previous stage and the outcomes of the second stage will offer a complete profile of the organization. The third stage is choose the cloud provider and cloud migration implementation, the main aim of this stage is to choose the best cloud provider based on cost and the services offered. Finally, the last stage is post-implementation. It consists of two steps, which are create plan for moving from one provider to other and plan for stop cloud services. The benefit of the proposed framework is that the web based tool can be used by education entity at the initial stage, to assist these entities to evolve and move to the cloud computing technology with minimal risks.
\end{abstract}

\section{Keywords}

Cloud Computing, Educational Cloud, KSA, Resources Sharing, Software Engineering.

\section{INTRODUCTION}

Cloud Computing is evolving as a key technology for sharing resources. It can be defined as a shift from local computing offerings to external cloud provider [2]. The benefits of cloud are documented and defined by Badger et al. [2]. The document presents the major classes of cloud technology and provides guidelines for organizations on how to define the related advantages and risks of migration to cloud computing. Moreover, the document introduces different technologies and structures to adapt to the various requirements of organizations.

\section{MOTIVATION AND GENERAL CONSIDERATION}

During the past 10 years, the higher education sector in the Kingdom of Saudi Arabia has witnessed a qualitative and quantitative transformation [3]. This is due to the strategic importance of the development of human resources in the Kingdom. The main goal of this transformation is to lead the country a development path and to foster prosperity in the knowledge domain. Because of this strategic decision, the number of students in higher education has grown over the last few years [3]. Higher education, in particular, is the primary foundation of economic and social transformation. Consequently, the Kingdom of Saudi Arabia strives to make use of all its human, material and spiritual resources to reach the most distinguished levels locally, regionally and internationally [3].

The following figure illustrates that the number of students who attended Saudi Educational system in 2003 increased sharply in 2013 due to improved interest in education in the Kingdom of Saudi Arabia [4].

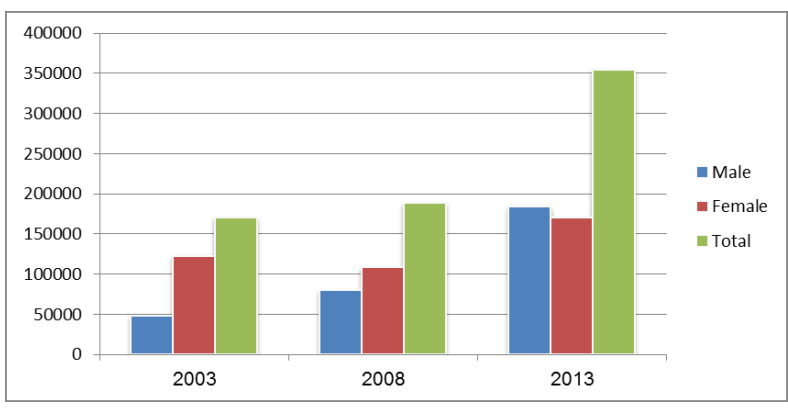

Figure 1: Number of students in Saudi Educational system from 2003 to 2013 [4]

Essentially, the Saudi higher education system started to face the issue of quality from two vital dimensions [5]. The first issue is improving the internal efficiency of universities by ensuring high quality of the education offered. This issue was addressed through the establishment of the National Center for Assessment in Higher Education in 2000 AD. The second issue is improving external efficiency of universities by achieving institutional accreditations. To achieve this goal, The National Commission for Assessment and Academic Accreditation (NCAAA) was established in 1424 AH to be responsible for academic accreditation and quality assurance in higher education institutions [5]. In the context of supporting the efforts of the universities and the higher education programs to reach advanced levels, the ministry has 
taken a number of qualitative initiatives aimed at raising the level of quality in universities. These initiatives are represented in three major projects [5]. The first project pertains to developing creativity and excellence of the faculty members. The second one pertains to supporting the establishment of centers for research and scientific excellence in universities, in addition to what is approved in their budgets. The third project is to collaborate with universities in supporting scientific societies [5].

Cloud provides on-demand resources and services. The resources include servers, platforms, infrastructure, and applications. The services include data management, network access, and applications management [1]. There are many reasons for adopting cloud. First, cloud is a cheaper substitute to purchasing and maintaining in-house system infrastructures. Second, it can eliminate countless supportrelated matters [1]. Cloud provides dynamic scalability, elasticity of resource availability and profitable usage. Educational cloud imposes challenges that need to be studied [6]. These challenges include the technology, the information systems made for teaching, integration of resources, and systems' developments. Integration involves the hardware, software and the overall infrastructure that can serve teaching and learning purposes [6].

A previous study conducted by Radhakrishnan et al. [7] covered three main issues. The first one is educational cloud which focuses on distance education objectives such as information resource management, online course building, and information systems applications among other aspects. The second one is educational cloud for campus teaching. Among other aspects, this one focuses on campus network management and Campus educational cloud model. The third issue is how to apply educational cloud on the cloud successfully. It focuses on the common success factors that ensure success of the educational cloud implementation [8]. Over the last four years, many researchers have examined educational cloud implementation. Hirsch et al. [9] suggested an approach to unify cloud learning and mobile learning, which is called "Mobile Cloud Education". Besides, they investigated the problems experienced in the cloud education. According to their research, integration is a problem because it needs different services that must communicate with each other [9]. In order to use cloud, two dissimilar aspects services and data need to be addressed [9]. Services are the functionalities. The data available in the cloud is processed into information. Another problem is assessment. This problem embodies new models of learning. In order to achieve this level of service, data must be analysed and stored in a way that is easier to search and retrieve. Additionally, in relation to students' work, tools must be developed to trap plagiarism [9].

The remainder of the paper is organized as follows. In Section II, we introduce the problem statement for migration of higher educational resources to KSA, Section III presents the proposed frame work, In Section IV the Implementation details of the proposed framework are presented, Section V presents the results and discussions, and finally Conclusion is presented in Section VI.

\section{PROBLEM STATEMENT}

The Kingdom of Saudi Arabia is striving to catch up with the swift improvements in technology within its own infrastructure. The education system is the basic pillar for the advancement of a nation. The government of Saudi Arabia is aware of this and always sets aside huge budgets for education development [4]. Educational Cloud computing is a promising technology that encourages learning with reduced cost. It is also accessible all the time from anywhere and is devoted to the idea of life-long-learning. Adopting Educational Cloud computing technology needs to be studied in order to define its value and its mechanism of implementation [8].

Current higher educational settings are traditional in nature and are often unable to face the demand for rapid changes in technologies in an interactive learning environment. The same is true for e-learning which appears to have numerous limitations starting from the use of local surroundings. In addition, infrastructure limitations often force institutions to avoid using multimedia contents in synchronized form due to the cost involved. Because of these and many other limitations, institutions often eliminate the use of sophisticated educational platforms [7].

This paper is intended to create a framework that identifies the requirements which will justify the implementation and assisted migration of educational cloud for higher education institutions in KSA.

\section{THE PROPOSED FRAMEWORK}

The proposed framework has four stages as presented in the figure bellow. It's a bottom-up approach.

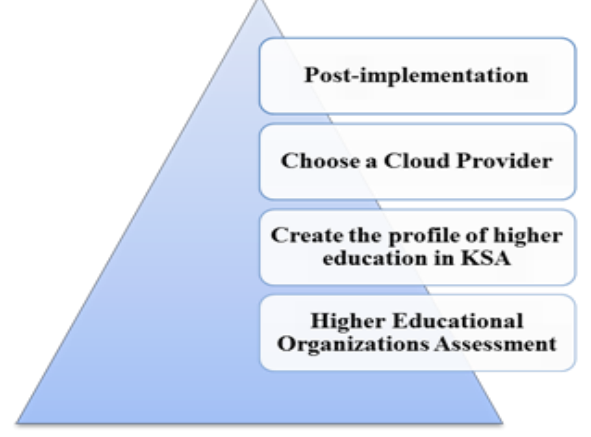

Figure 2: The Proposed Framework

The framework intended to answer the following objectives:

A. What are the required modifications of the previous implementations of educational cloud to fit into the Saudi Higher Education Systems?

B. What is the needed change in the current education system in KSA to be transformed into an educational cloud system?

For the first objective, the dependent variable is the Requirements Identification for Migration of Higher Educational Resources to Cloud.

The independent variables include the following:

I. Assessment: The means of evaluating students using the educational cloud services. Hirsch et al. [9] emphasized that one of the problems of such implementation is how to track students' performance in order to evaluate them.

II. Plagiarism detection: The methods and technologies of checking whether students' papers are plagiarised [9].

III. Services needed for higher educational cloud: eLibrary, e-Course, e-Academic, e-Learning, and e-Lab [10].

IV. Data needs to manage: Library collections, learning materials, scientific publications, student IDs, professor's profile, and higher education profile [10]. 


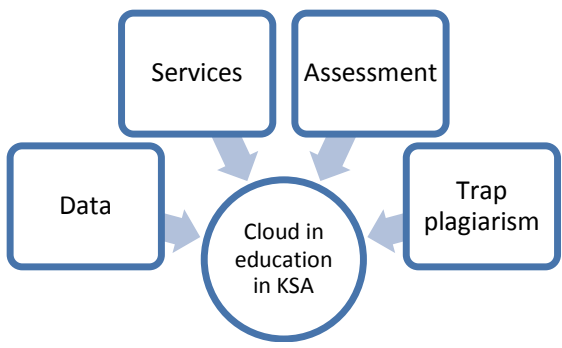

Figure 3: Dependent and independent variables

\subsection{First Stage: Higher Educational Organizations Assessment}

The assessment of higher educational organizations is the first tasks. The assessment has to be done before selection of cloud services and migration. Before the implementation of cloud, the organizations must determine their economic objectives, as they relate to, finances, customers, internal infrastructure, and learning-development. They should then identify ways in which cloud services can tolerate these objectives [11]. The various steps in this stage include the following:

1.Create a cross-analysis to resolve critical limitations that may delay migration to the cloud. Beserra, et al. [12] provide a profile template that any organization can fill based on its context, objectives and processes. Then, a cross-analysis can be done to resolve critical limitations that may delay migration to the cloud

2.Use Suitability Index model for Adoption to Cloud as proposed by [13]. This step complements the previous step, and it considers various incorporeal impacts of cloud with the aim of getting an accurate estimation of cloud outcomes.

3.Assess the potential risks as presented by Khajeh-Hosseini et al. [14]. This step intended to evaluate the risks that might threaten the cloud migration or decrease the outcome of such migration.

4.Use Decision Model proposed by Brisken et al. [15]. The model assists an organization in estimating the benefit of leasing from storage clouds. The authors present a model for calculating a reasonable approximation of the possible outcomes.

\subsection{Second Stage: Create profile for Higher education organization in KSA}

The second stage in the framework involves creating the profile for higher education in KSA [12]. Organization profiles must be created through a cross-analysis to resolve critical limitations that may delay migration to the cloud. The outcomes of the previous stage and the outcomes of this stage, will offer a complete profile of higher education in KSA:

1.The mission of higher education must be changed from the resources practise to provision of services; this requires change in the strategic goals of the organization [16].

2.Implement the Stakeholder Impact Analysis and Responsibility model. This is very important as the results vary from one organization to the other [17].

3.Identify the security and privacy policies to identify security and privacy constraints according to organisational context, goals, actors, tasks, resources, and plans [18].

4.Plan for Student Assessment [9].
5.Plan for plagiarism detection and penalties policies [9].

\subsection{Third stage: Choose a Cloud Provider and Cloud Migration Implementation}

The aim of this stage is to choose the best cloud provider based on cost and the services offered. This is done using the following, steps.

1.Collect data about the different cloud providers and their offers [19]. The data should include the type of services they provide.

2. Choose the best cloud provider based on the proposed model by Menzel et al. [20]. According to the Quality of Service (QoS) parameters, the framework performs selection of cloud provider.

3. Follow the suggested guidelines for choosing the best cloud provider [21].

4.Migrate to the cloud, based on the outcomes of the previous stage.

\subsection{Fourth Stage: Post-implementation}

The aim of this stage is to prepare for changes after migration to cloud. The changes are of two types, which are changing the cloud provider or stopping the cloud services. Badger et al. [2] states that organizations must develop a plan for migrating the data to and from the cloud. In addition, the organization must prepare for interactions with the data resident in the cloud. Customers must plan for a termination of a provider's service, and should clarify how assets are to be returned back

1.Create a plan for moving from one provider to other

2.Create a plan for termination (stop cloud service).

\section{IMPLEMENTATIONS OF THE \\ FRAMEWORK}

In this section, implementations of the framework are explained to demonstrate its validity and applicability. The case study of framework implementation is demonstrated as well as the results of the case study as implemented using the web-based tool.

\subsection{Application Implementation}

An application is developed to implement the framework automatically step by step to ensure the ease of using the framework. The web-based tool is developed using ASP.net and C\# programming language. ASP stands for Active Server Pages; .NET is also a framework that more or less defines a virtual machine along with thousands of objects that are useful building blocks for any program [22]. It is Microsoft's technology for building dynamically generated web pages. It was introduced in 2002 [22]. C\# is intended to be a simple, modern, general-purpose, object-oriented programming language [23]. The web-based tool has two screens; first one presents the questions to the user and gets the answers. The second one presents the results, which include decision of migration, type of migration and the best-fit cloud provider. Then, reports of all the inputs, which are the system specifications and constraints of the university, are illustrated to help the university focus on important points.

\subsubsection{Case Study of Framework Implementation in PSU}

The Prince Sultan University wants to become the leading non-profit, private university in the Middle East, providing a quality education equal to other reputable universities in the world. It purposes to provide the KSA with quality education of the highest international standards [24]. In its efforts to 
achieve successful and responsible life-long learning, PSU integrates modern technology, pedagogy and human values for the advancement of scientific research, productivity and leadership with a more meaningful social life [24]. PSU information is used as a case study to test the web-based tool to determine the feasibility to move the university to cloud. PSU wants to move applications and hardware to cloud to provide capacity-on-demand computing for its internal users and external user who turn to university for IT processing or access to their account.

First Stage: Higher Educational Organizations Assessment: Results of First Stage:

\section{Cross Analysis Results}

Cross analysis defines the legal and administrative issues and information that are relevant to the migration task such as policies, guidelines, laws, rules or procedures shown in Figure 4. The constraints for migration and evaluation of organizational constraints are shown in Figure 5. The functional and non-functional requirements of the application and technologies used by the applications are shown in Figure 6.

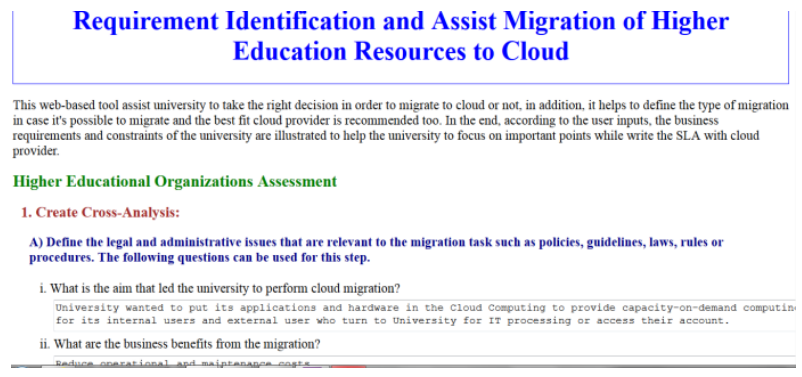

Figure 4: Cross analysis step 1

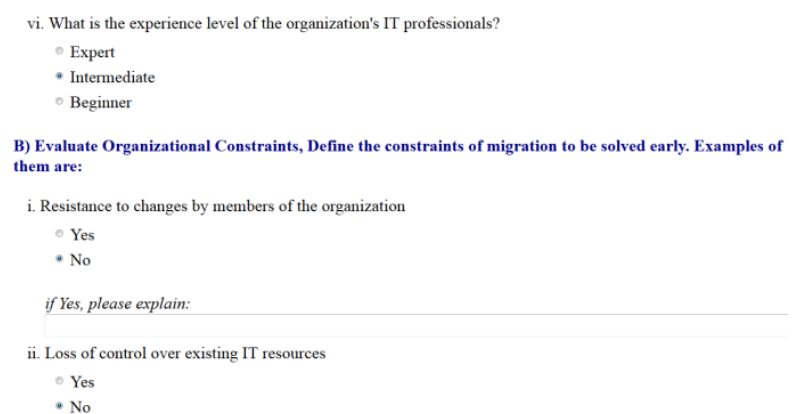

Figure 5: Cross analysis step 2

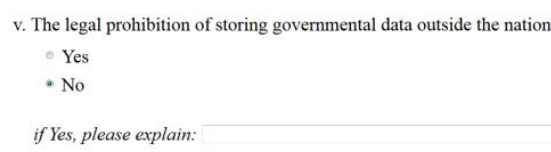

i. Define the functional and non-functional requirements of the application/s Functional Requirement:

\section{Suitability of Organizations for Adoption to Cloud} Results

The Suitability Index model is presented in this section. The model includes several steps such as size of the IT resources and the usage patterns [Figure 7]. The highly critical work that requires most of the resources, platforms, applications and security are defined. Weights are assigned for factors that affect the suitability index as shown in Figure 8.

2- Identification of Organizations Suitability for Adoption to Cloud

A) Define the size of the IT resources.

$$
\begin{aligned}
& \text { i. The number of Servers: } \\
& \text { ii. The annual revenue for IT } \\
& \text { iii. Number of project per year }
\end{aligned}
$$

35
300000
$\$$

B) Define the usage patterns.

i.Define the peak usage including:

- The duration of peak usage per year.

\begin{tabular}{|c|c|}
\hline \multicolumn{2}{|c|}{ Registration, Academic and assessment results } \\
\hline \multicolumn{2}{|c|}{ vii. Assigning various weights for each factor: } \\
\hline Characteristics & Weight (Credit) \\
\hline Size of IT resources & 7 \\
\hline Number of servers & 8 \\
\hline - Less than 100 servers & 4 \\
\hline - From 101 to 2000 servers & 3 \\
\hline O From 1001 to 10,000 servers & 2 \\
\hline - 10,001 to 50,000 servers & 1 \\
\hline Number of countries its spread across & 4 \\
\hline - One Country & 5 \\
\hline
\end{tabular}

- The average number of times of the peak occurrence per year.

Figure 7: Suitability Results step 1

Figure 8: Suitability Results part 2

\section{Risk Assessment Results}

The risks that may happen as a result of the migration process in PSU are shown in Figure 9.

\section{Assess the potential risks}

\begin{tabular}{|c|c|c|}
\hline & ID & Risk \\
\hline a & R1 & Organizational: Loss of control over resources \\
\hline$\approx$ & R2 & Organizational: Reduced staff productivity during the migration \\
\hline a & R3 & Organizational: Managing a system deployed on several clouds can take extra management effort \\
\hline v & R4 & Organizational: Change to other cloud providers and its consequences. \\
\hline $\mathrm{x}$ & R5 & Organizational: Resistance to change from changes to people's work. \\
\hline घ & R6 & Organizational: Mismatch between existing incident handling procedures and cloud providers' procedures. \\
\hline × & R7 & $\begin{array}{l}\text { Legal: Unusable sotware licenses on the cloud due to the license using traditional per-seat or per-CPu licensing } \\
\text { agreements etc. }\end{array}$ \\
\hline
\end{tabular}

The following table identifies the common risks that may happen as a result of migration process. Please, choose the potential risks from the table to provide you the mitigation approaches suggested

Figure 9: Risk Assessment

\section{Decision Model}

To evaluate the benefits of purchasing compared to renting storage from a cloud, the Decision Model proposed by Brisken et al. [15] used as shown in the Figure10.

Figure 6: Cross analysis step 3 
4.Use Decision Model

Please fill the following table:

\begin{tabular}{|l|c|}
\hline \multicolumn{1}{|c|}{ item } & Value \\
\hline Cost of electric utility (\$/Kilowatt hour) & 0.4 \\
\hline Size of purchased disk drives (GB) & 20000 \\
\hline Proportional difference between human effort versus storage infrastructure & 500000 \\
\hline Used disk deprecation factor on salvage $[(0.0,1.0)]$ & 0.1 \\
\hline Disk controller unit cost (\$) & 500 \\
\hline Annual Human operator salary for year 1 (\$) & 80000 \\
\hline Annual Human operator salary for year 2 (\$) & 90000 \\
\hline
\end{tabular}

Figure 10: Decision Model

Second Stage: Create the profile of higher education in KSA: Results of Second Stage:

\section{Stakeholder Impact Results}

The Stakeholder Impact Analysis involves social and political issues that may affect migration to the cloud. The analysis consists of defining key stakeholders and changes in performing their tasks. It also involves defining the consequences of the changes considering the stakeholder's time, resources, values, capabilities, status and satisfaction. Stakeholder Impact analysis also analyzes these changes to scope on wider effect such as the relationships between individuals or groups to which stakeholders belong. Finally, defining whether the stakeholder will accept the change based upon their relational surroundings [See Figure 11].

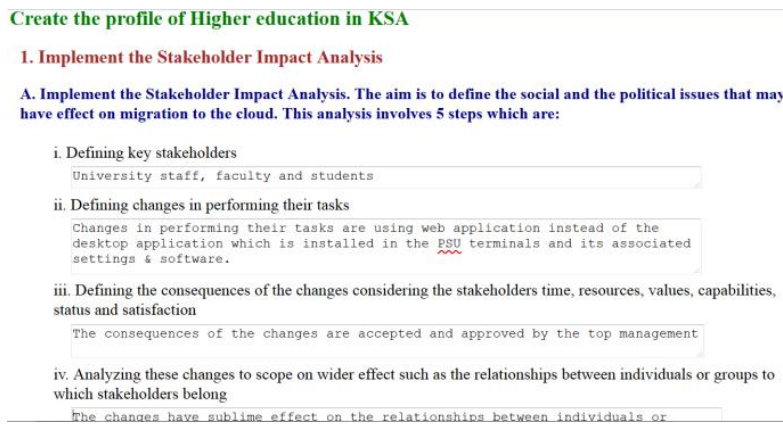

Figure 11: Stakeholder Impact Analysis

2. Results of Identifying Security and Privacy Policies The security and privacy policies are identified. They include data integrity characteristics, data availability, network availability and other constraints such as quality of service (QoS) based on response time, throughput, reliability and scalability, as shown in Figure 12.

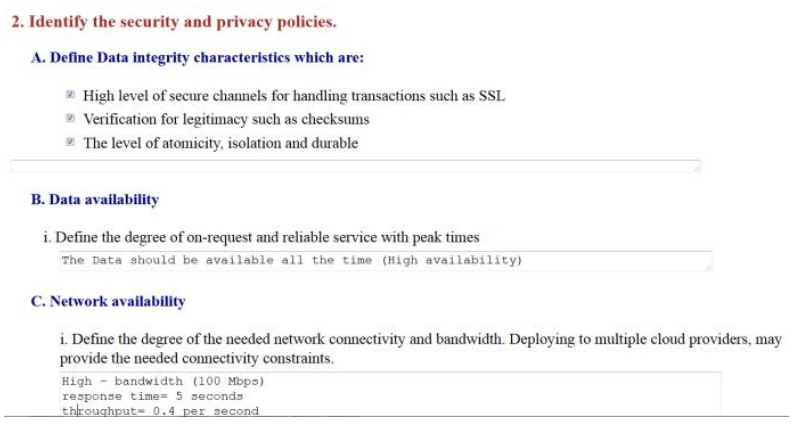

Figure 12: Security and privacy policies

\section{Plan for Students Assessment Results}

The plan for Student Assessment is shown in Figure 13.

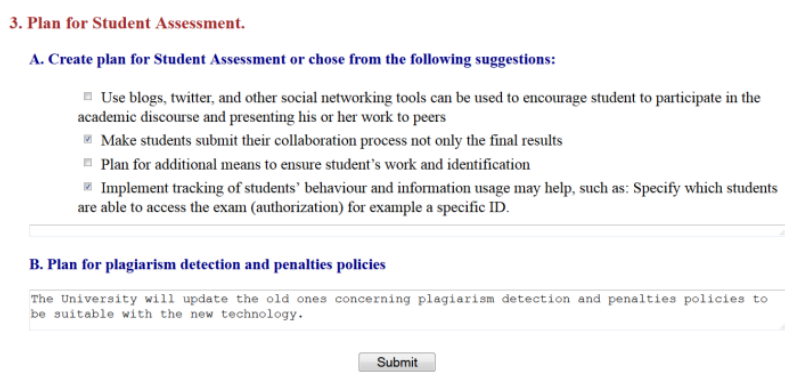

Figure 13: Plan for Student Assessment step

Final Result:

The results of evaluation of the framework includes decision that defines if it is possible to migrate to cloud or not, the type of migration if possible, and the best-fit cloud provider, as shown in Figure 14. The result shows that "partial migration to the cloud" is the best option for PSU, and the best cloud provider for PSU is STC. The recommendations and system specifications of the university are illustrated in the report [Figure15]. The report includes the risks that may happen as a result of migration process and the appropriate mitigation approaches related to each risk [Figure 16].

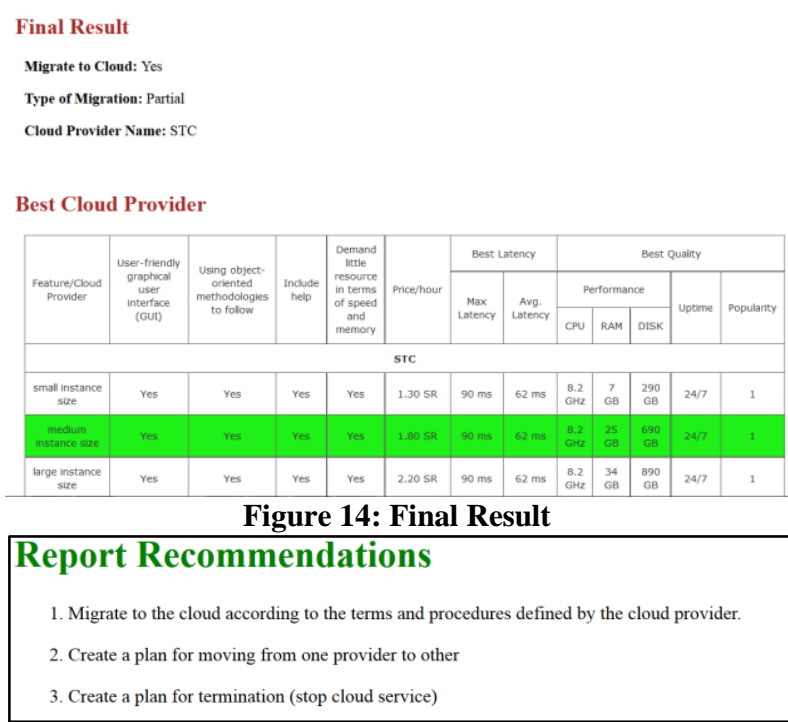

Figure15: Report recommendations part 1

The following table identifies the common risks that may happen as a result of migration process and the mitigation approaches suggested.

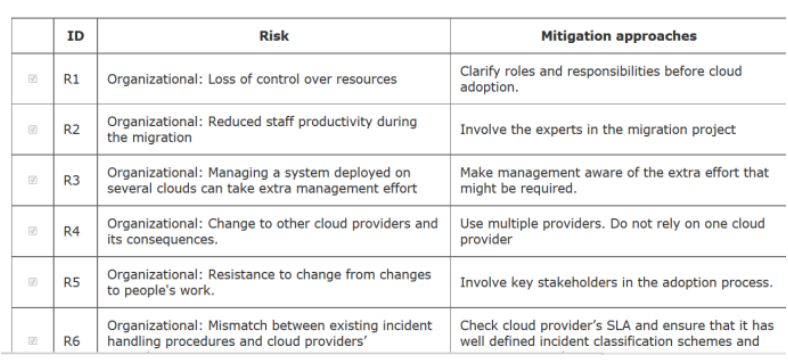

Figure 16: Risk Assessment Result 


\section{RESULTS and DISCUSSIONS}

This section elaborates the data analysis, final modifications, and justifications as well as the results of the case study, as implemented using the web-based tool.

\subsection{Results of the Framework Implementation}

A case study involved step-by-step implementation of the framework in Prince Sultan University.

\subsubsection{Analysis of the Case Study Results}

\section{First Stage: Higher Educational Organizations}

Assessment:

The legal and administrative issues are defined. The University wanted to put its applications and hardware in the cloud to provide capacity-on-demand computing for its internal users and external users who turn to the University for IT processing or to access their account. The business benefit is to reduce operational and maintenance costs. The organizational constraints include:

- Confidentiality of data prevents sharing all the data with external entity such as the cloud provider.

The applications' profile is defined by identifying the functional and the non-functional requirements. The Functional Requirements include input formats, sorting, special cases, and boundaries and error conditions. The NonFunction Requirements include performance, real-time, modifiability, flexibility, usability, privacy, legal issue, and security. The technologies used include .NET, PHP, and SQL server.

The Suitability Index model is performed, and according to the decision of suitability of a university for adoption of cloud, the Suitability index is above 4600. Therefore, the PSU is suitable for the adoption of cloud. The risks provided in the framework are to be considered and mitigated. The Decision Model resulted in an NPV value of less than zero, which means migrate to cloud.

\section{Second Stage: Create the profile of Higher education in} KSA:

The PSU top management and stakeholders are interested in migrating to the cloud. They provided policies and facilities to enable the migration including providing the necessary information for this research to study the feasibility of cloud migration. The stakeholder impact analysis is performed and changes in performing the tasks are sublime. In addition, the consequences of the changes are accepted and approved by the top management. The Responsibility Model is not implied, as there are no major changes to be planned for.

Concerning data integrity secure channels for handling transactions such as SSL are needed. Verification for legitimacy such as checksums is necessary. Moreover, features such as atomicity, isolation and durability must be available. The Data should be available all the time. Concerning the Network availability, high bandwidth of 100 Mbps is needed. Response time is to be 5 seconds. The throughput is 0.4 per second. The network must be reliable and scalable. Concerning student assessment the recommendations in the framework are to be implemented. Methods and policies for plagiarism detection and penalties are to be used.

Third stage: Choose a Cloud Provider and Cloud Migration Implementation:
The best cloud provider for PSU to provide cloud services is STC. The cloud provider is chosen based on recommendation presented by Mouratidisa et al. [18], by comparing some features between different cloud providers, for example Performance, best latency, and best quality.

\section{Fourth Stage: Post-implementation:}

They are to be implemented by the cloud consulting service provider.

\section{CONCLUSION}

In this paper a framework for Requirements Identification and assisted Migration of Higher Educational Resources to Cloud for KSA is implemented. Decision of suitability of an organization for adoption and migration to cloud is taken based on the Value of the Suitability Index and the Decision Model calculations. The Best cloud provider is selected based on the best quality of service, performance and popularity. The framework is validated and tested using the proposed web based tool. The report generated by the tool suggests that PSU is recommended for partial migration to cloud due to criticality of the data. The benefit of the proposed framework is that the web based tool can be used by education entity at the initial stage, to assist these entities to evolve and move to the cloud computing technology with minimal risks. Based on the characteristics of the organizational resources such as size of IT resources, utilization of resources, sensitivity of data, and criticality of the work to be carried out by the organization, decision for adoption and migration of organizational resources to cloud is provided. The main limitations in this research, is to define accurate information about cloud provider services, and lack of a cloud provider's database that can offer updated information about the cloud providers offers, services and prices.

\section{REFERENCES}

[1] F. Alshwaier, A. Alshuwaier and A. Areshey, "Applications of cloud computing in education," in IEEE 8th International Conference on Computing and Networking Technology (ICCNT), Gueongju, 2012, pp. 26-33.

[2] L. Badger, T. Grance, R. Patt-Corner and J. Voas, "Draft Cloud Computing Synopsis and Recommendations," In National Institute of Standards and Technology, Gaithersburg, Special Publication 800-146 2012.

[3] Saudi Embassy. (2014, June 9). About Saudi Arabia [Online].Available: http://www.saudiembassy.net/about/countryinformation/education/

[4] Ministry of Education-Higher Education. (2014, June 11).Students[Online].Available: http://www.mohe.gov.sa/en/studyinside/universitiesStatis tics/Pages/Students.aspx

[5] Ministry of Education- Higher Education. (2015, June 9).Achievements and aspirations [Online]. Available: http://mohe.gov.sa/en/aboutus/Pages/Achievements-andaspirations.aspx

[6] C. Li, R. Dutta, C. Kloppers, C. D'Este, A. Morshed, A. Almeida, and J. Aryal, "Mobile Application Based Sustainable Irrigation Water Usage Decision Support System: An Intelligent Sensor CLOUD Approach" in SENSORS, IEEE , Baltimore, 2013, pp. 1 - 4. 
[7] N. RadhaKrishnan, N. Chelvan, and D. Ramkumar, "Utilization of cloud computing in E-learning systems " in Cloud Computing Technologies, Applications and Management (ICCCTAM), International Conference, Dubai, 2012, pp. 208-213.

[8] M. Alabbadi, "Cloud Computing for Education and Learning: Education and Learning as a Service (ELaaS)," in Interactive Collaborative Learning (ICL), 14th International Conference, Piestany, 2011, pp. 589-594.

[9] B. Hirsch and J. Ng, ,"Education beyond the Cloud: Anytime-anywhere learning in a smart campus environment," in IEEE International Conference Internet Technology and Secured Transactions (ICITST), Abu Dhabi, 2011, pp. 718-723.

[10] N.Cenka ，B. Anggun and A.Hasibuan , "Enhancing educational services using cloud technology," in Information and Communication Technology (ICoICT), International Conference, Bandung, 2013, pp. 155 - 160.

[11] G. Avram, "Advantages and Challenges of Adopting Cloud Computing from an Enterprise Perspective," in Procedia Technology, 7th International Conference Interdisciplinarity in Engineering, Tirgu Mures, 2013, pp. 529-534.

[12] P. Beserra, A. Camara, R. Ximenes,A.Albuquerque, N. Mendonça, "Cloudstep: A step-by-step decision process to support legacy application migration to the cloud," in Maintenance and Evolution of Service-Oriented and Cloud-Based Systems (MESOCA), 2012 IEEE 6th International Workshop, Trnto, 2012, pp. 7 - 16.

[13] S. Misra, A. Mondal1, "Identification of a Company's Suitability for the Adoption of Cloud Computing and Modelling its Corresponding Return on Investment," Mathematical and Computer Modelling, vol. 53, no. 3-4, pp. 504-521, February 2011.

[14] A. Khajeh-Hosseini, D. Greenwood \& I. Sommerville, "Cloud Migration: A Case Study of Migrating an Enterprise IT System to Iaas," in Cloud Computing (CLOUD), 2010 IEEE 3rd International Conference , Miami, 2010, pp. 450 - 457.
[15] W. Brisken and J. Romney, "To Lease Or Not To Lease From Storage Clouds," Computer, vol. 43, no. 4, pp. 44 50, April 2010.

[16] W. Zhou, B. Cui, Y. Wang, Q. Shi, S. Yokoi, "Exploration of Public Education Resource Sharing and Cloud Services," in Computer Science \& Education (ICCSE), 8th International Conference, Colombo, 2013, pp. 1277 - 1280.

[17] A. Khajeh-Hosseini, D. Greenwood, J. W. Smith, I. Sommerville, "The Cloud Adoption Toolkit: Supporting Cloud Adoption Decisions in the Enterprise," SoftwarePractice \& Experience, vol. 42, no. 4, pp. 447-465, April 2012.

[18] H. Mouratidisa, S.l Islama, C. Kalloniatisb, S. Gritzalis, "A framework to support selection of cloud providers based on security and privacy requirements," Journal of Systems and Software, vol. 86, no. 9, pp. 2276-2293, September 2013.

[19] Z. Song, "A Decision Support System for Application Migration to the Cloud," University of Stuttgart, Stuttgart, Master's Thesis 2013.

[20] M. Menzel, R. Ranjan, "Cloud Genius: Decision Support for Web Server Cloud Migration," in Proceedings of the 21 st international conference on World Wide Web, New York, 2012, pp. 979-988.

[21] H. Al-Bahadili, G. Issa and M. Abuhamdeh, "A hierarchical framework for evaluating success factors of M-learning," The Research Bulletin of Jordan ACM, vol. 2, no. 3, pp. 53 - 59, June 2011.

[22] Microsoft Corporation. (2015, March 2).ASP.net [Online]. Available: http://www.asp.net/get-started

[23] A. Hejlsberg, S. Wiltamuth, P. Golde, The C\# Programming Language, 2nd ed. Boston, US: AddisonWesley, 2004.

[24] Prince Sultan University. (2015, March 4).Vision and Mission [Online]. Available: http://www.psu.edu.sa/VisionMission.aspx 